\title{
Medicalização dos problemas de comportamento na escola: perspectivas de professores
}

\author{
Nilza Sanches Tessaro Leonardo, ` Mariana Akemi Suzuki \\ Universidade Estadual de Maringá, Maringá, PR, Brasil
}

\begin{abstract}
Resumo
Este estudo teve por objetivo investigar os efeitos do processo de medicalização de alunos que apresentam comportamentos que a equipe escolar considera inadequados. Participaram da pesquisa dez professores de três escolas públicas de uma cidade do Estado do Paraná. Para a coleta de dados foi utilizado um roteiro de entrevista semiestruturado. Os dados foram trabalhados mediante análise de conteúdo e os resultados mostraram que, na compreensão dos participantes, o aluno "medicado" consegue se concentrar mais e fazer as atividades em sala produzindo satisfatoriamente; porém questionam as consequências do processo de medicalização para a infância, uma vez que as crianças se tornam apáticas e não se relacionam mais com os colegas da maneira como se relacionavam antes. Concluímos que essa prática social da medicalização dos problemas de comportamento de alunos nas instituições escolares se torna uma prática social de controle, uma vez que com essa prática se buscam objetivos materiais ideológicos.
\end{abstract}

Palavras-chave: medicalização; problemas de comportamento; Psicologia Histórico-Cultural.

\section{Medicalization of behavior problems in school: teachers' perspectives}

\begin{abstract}
This study aims to investigate the effects of the process of medicalization of students who exhibit behaviors deemed inappropriate by school staff. Participants were ten teachers from three public schools in a city in the state of Paraná. For data collection we used a semistructured interview guide. The data were processed using content analysis and the results showed that the participants understand that medicated student can focus more, do the activities in the classroom, and starting to produce satisfactorily. However, they also questions the consequences of the process of medicalization for childhood, since they students become listless and not relate to other colleagues as they did before. We conclude that the social practice of medicalization of behavior problems of students in the school becomes a social control practice, since it is sought ideological goals with this action.
\end{abstract}

Keywords: medicalization, behavior problems, Cultural-Historical Psychology.

\section{Introdução}

Barros (1983, p. 378) define o processo de medicalização como:

[...] a ampliação crescente do trabalho de intervenção da medicina na vida das pessoas, passando para a alçada médica, inclusive, problemas claramente determinados pela forma de ser da sociedade, no interesse de se manter o status quo (por exemplo, escamoteando os conflitos inerentes às relações capital-trabalho).

Segundo Conrad (2007), medicalização também diz respeito a um processo em que problemas não médicos acabam se transformando em problemas médicos, apresentando características de doenças e desordens em nível orgânico. Nesse mesmo sentido, para Kantoviski e Vargens (2010), o processo da medicalização refere-se à transformação das questões da vida cotidiana em objetos da medicina ou, ainda, à capacidade do saber médico de se apropriar dos problemas cotidianos e dar explicações a esses problemas por meio de conhecimentos da medicina. Os (as) autores (as) desenvolvem ainda uma discussão em torno da sociedade capitalista. A partir dessa discussão, a medicalização seria uma forma de controle social que normatiza, regula e administra diversos aspectos da vida humana. Para Moysés e Collares (2010),

\footnotetext{
* Endereço para correspondência: Universidade Estadual de Maringá, Público, Cch Psicologia. Avenida Colombo, 5790 - Jardim Universitário CEP: 87020 900 - Maringa, PR - Brasil.E-mail: nstessaro@uem.br, marisuzuki@uol.com.br
}

esses aspectos da vida humana se referem às relações socialmente construídas, o que significa que o processo de medicalização naturaliza a vida e desafia os direitos humanos, que são uma conquista da sociedade, e não um aspecto biológico.

Nesta mesma direção, Garrido e Moysés (2010, p. 150) afirmam que "Medicalizar [...] significa também acreditar que o saber médico poderá levar ao domínio da morte e que a frequência das curas está diretamente ligada à intensidade do ato médico". Sob esta ótica, quanto mais o médico fizer parte de nossa vida, quanto mais teremos a possibilidade de ter a vida "normalizada".

Assim, é, por meio do discurso moralizador da medicalização da vida das pessoas que esse processo adentra também na instituição escolar, adquirindo características e nomes diferentes, que, à primeira vista, não são percebidos como uma forma de controle social. Quando tratamos da moralização das condutas humanas estamos querendo afirmar exatamente que a produção humana acompanha a produção dos comportamentos e sentimentos humanos. Assim, a medicalização da vida torna-se presente em várias situações da vida, como a familiar, a escolar, a do trabalho e a da cultura (CONRAD, 2007).

Entre as diferentes maneiras de a medicalização se inserir nas escolas, podemos citar o uso da medicação na infânciaescolarpararesolverdificuldadesdeaprendizagem 
e comportamentos considerados inadequados, fato que provoca muita discussão entre a comunidade científica, já que não se sabe das consequências que esse uso desenfreado dos medicamentos possa ocasionar futuramente a esses alunos (GARRIDO; MOYSÉS, 2010; EIDT; TULESKI, 2010). De acordo com Eidt e Tuleski (2010), em termos clínicos, os médicos não têm clareza do quadro que define cada transtorno. Nos manuais de transtornos mentais, como o DSM-IV (AMERICAN PSYCHIATRIC ASSOCIATION, 1994), apresentam-se apenas os sintomas de cada doença e não se encontram as explicações para elas, tornando-se os diagnósticos e intervenções confusos e incertos.

Os diagnósticos de TDAH (Transtorno de Déficit de Atenção e Hiperatividade) e dislexia apresentam-se igualmente confusos e incertos. De acordo com Leite (2010); Moysés e Collares (2010), é de se questionar a existência do TDAH como um transtorno que provoque uma disfunção nas capacidades de atenção do aluno, uma vez que existe uma imprecisão dos diagnósticos feitos em crianças escolares.

Segundo Caliman (2008), o diagnóstico do TDAH, apesar de ser um dos mais estudados no campo neuropsiquiátrico, também é tido como um dos mais "controversos" da atualidade. Escreve a autora:

Esse diagnóstico tem sido descrito como uma "polêmica" de interesse internacional, que desconhece barreiras culturais e sociais. Os paradoxos em torno do transtorno invadem a mídia mundial, que tem divulgado o TDAH como diagnosis du jour boutique disorder psychofade a Ritalina como "pílula da obediência". Além disso, suas controvérsias são discutidas pelos profissionais mais importantes do campo da neuroética, das ciências humanas e sociais (CALIMAN, 2008, p. 560).

Segundo a autora, os estudos realizados no campo citado caminham em direção não apenas de apontar os prejuízos que este transtorno causa ao indivíduo, mas sobretudo de demonstrar que este é determinado por fatores biológicos, genéticos e cerebrais. Assim sendo, o discurso da neuropsiquiatria dominante se resume no seguinte: "[...] o diagnóstico do TDAH é real porque, em certa medida, é visível e biológico, e descreve uma condição maligna" (CALIMAN, 2008, p. 560). De acordo com a autora, essa afirmação não pode eximir médicos e psicólogos e outros profissionais, sejam eles da área de saúde ou da educação, de considerarem "[...] todos os aspectos, individuais, econômicos, morais e sociais envolvidos em sua clínica" (CALIMAN, p. 2008, p. 565).

Outro aspecto preocupante e alarmante relacionado ao TDAH, sobretudo no âmbito da escola, é o elevado número de crianças em idade escolar que estão sendo diagnosticadas com este transtorno e fazendo uso de medicação. Segundo Moysés e Collares (2010), nos Estados Unidos, entre 1990 e 1995, houve um aumento de $600 \%$ na produção e no uso do metilfenidato, e as estatísticas da ONU apontavam que a produção e o consumo de psicotrópicos nos EUA eram cinco vezes maiores que no restante do mundo. No Brasil, a venda da Ritalina (nome comercial do medicamento metilfenidato, muito utilizado nos diagnósticos de TDAH) ou "droga da obediência"- nome popular pelo qual ficou conhecida - foi de 70.000 caixas no ano 2000, e no ano de 2009 número de vendas chegou a 1.700 .000 caixas. "[...] no ano de 2008 gastou-se cerca de 88 milhões de reais com a compra de metilfenidato no Brasil" (MOYSÉS; COLLARES, 2010, p. 96).

Brzozowski e Caponi (2013) fazem um alerta sobre as consequências do excesso da medicalização dos comportamentos considerados inadequados entre escolares, em que vêm sendo tratados como patológicos comportamentos de crianças que na essência são normais. Essas autoras são categóricas ao afirmarem que "[...] enquadrar uma criança em um diagnóstico psiquiátrico apresenta sérias consequências indesejáveis, e acaba sendo mais útil para a sociedade e para o entorno da criança do que para a própria criança" (BRZOZOWSKI; CAPONI, 2013, p. 209)

Vale destacar que a construção de todo esse processo medicalizante vem acompanhada de uma prática de mais de cem anos de história. Para Boarini e Borges (2009), Na educação escolar os psicotrópicos ${ }^{1}$ vêm sendo ministrados pela Medicina há pelos menos um século e meio, e mais recentemente, esse uso vem sendo respaldado pelas áreas da Fonoaudiologia e Psicologia; no entanto, o uso desses instrumentos não tem contribuído para a diminuição da precarização do ensino, pois as escolas continuam apresentando um alto de índice de crianças com problemas de aprendizagem e comportamento.

Pesquisadores como Gusmão (2009), Luengo e Constantino (2009), Guarido (2007), Guarido e Voltolini (2009), Valentine (2010), dentre outros, apontam que a compreensão desses problemas de forma individualizada e organicista levam a denominar como distúrbios comportamentos considerados inadequados - como indisciplina, falta de atenção, agressividade e agitação do aluno.

Collares e Moysés (2010, p. 197) alertam para o perigo em biologizar as questões sociais, por deslocar “[...] o eixo de uma discussão político-pedagógica para causas e soluções pretensamente médicas, portanto, inacessíveis à educação. A isto, devemos chamar medicalização do processo ensino-aprendizagem. [...]". Com a medicalização dos processos escolares as soluções são transferidas para o campo da saúde e isenta-se o contexto escolar da responsabilidade por essa condição, “[...] criando ou ampliando um novo mercado de trabalho para avaliar, diagnosticar e tratar doenças no processo ensinoaprendizagem" (SOUZA; CUNHA, 2010, p. 225).

$\mathrm{Na}$ realidade, os problemas de comportamento de escolares precisam ser compreendidos e analisados a partir de uma perspectiva em que estes fenômenos sejam considerados como produzidos historicamente. Eles devem ser entendidos na totalidade das relações produzidas, englobando fatores educacionais, sociais, políticos e históricos, pois é na interação com o outro que o indivíduo supera sua condição biológica, sendo

${ }^{1}$ Termo utilizado para designar medicamentos de uso psiquiátrico. 
a transmissão da cultura, ou melhor, a aprendizagem, segundo Leontiev (1978), o que proporciona ao indivíduo adquirir as características e capacidades humanas, do mesmo modo que ele desenvolve as funções psicológicas superiores (atenção, memória, pensamento abstrato, etc.).

Para Vigotski (1991), os fatores biológicos são preponderantes no início da vida da criança e são responsáveis pelas funções psicológicas elementares reações automáticas e ações reflexas. Leontiev (1978) complementa expondo que as funções psicológicas superiores, que são especificamente humanas, formamse nas relações sociais entre os homens, no processo de produção da vida, por meio da apropriação da cultura humana transmitida de geração a geração.

Não obstante, o que temos observado é a prevalência de uma compreensão individualizante dos problemas no processo de escolarização, em desconsideração aos aspectos sócio-históricos, o que tem levado ao consumo cada vez mais abusivo de medicamentos que prometem resolver problemas emocionais e comportamentais de alunos e adultos.

Neste contexto, o presente trabalho teve por objetivo investigar os efeitos do processo de medicalização de alunos que apresentam comportamentos tidos pela equipe escolar como inadequados.

\section{Metodologia}

Quanto à questão metodológica deste estudo, entendemos que a abordagem materialista-histórica da realidade busca, a partir da realidade específica e mais subjetiva (como os relatos dos professores), a análise e compreensão da realidade objetiva do processo de medicalização. Dessa maneira, selecionamos o recorte de falas das entrevistas como uma das formas de chegar a essa análise.

Para Boarini (BOARINI; BORGES, 2009, p. 23), a entrevista permite que reconstruamos "[...] com todo o seu dinamismo e particularidade os acontecimentos históricos de um passado próximo 'ignorado ou silenciado"'. A autora enfatiza que por essa técnica podemos captar os detalhes mais sutis do objeto estudado, como o sentimento e uma singularidade que se expressa nos indivíduos.

Assim, podemos pensar a entrevista como um recurso importante para captar nos próprios professores algumas singularidades, como relatos e sentimentos. Consideramos que a análise científica da realidade apresentada nas entrevistas com os professores pode contribuir para uma compreensão não cotidiana da medicalização dos processos escolares. Utilizamos, para isso, a abordagem da Psicologia Histórico-Cultural.

\section{Participantes}

Esta pesquisa foi realizada com dez professores de três colégios estaduais de uma cidade do Interior do Estado do Paraná. Dos dez entrevistados, oito são mulheres. A média de idade dos entrevistados é de 39 anos, sendo que dois participantes têm idade entre 20 e 30 anos, quatro têm entre 31 e 40 anos, três entre 41 e 50 anos e um tem entre 51 a 60 anos de idade.

Dos dez entrevistados, dois possuem graduação em mais de um curso superior - portanto, a quantidade de cursos superiores dos entrevistados é mais que dez. Dessa forma, coletamos os seguintes números de diferentes cursos superiores: Geografia (3); Pedagogia (1); Matemática (1); Letras (3); Artes Visuais (1); Educação Física (1); Arte (1); Filosofia (1).

A respeito do tempo de experiência profissional, a média de anos de trabalho é de 14,4 anos, sendo que, dos dez entrevistados, cinco possuem tempo de experiência entre um e dez anos; dois contam entre onze e vinte anos de trabalho; e três, entre 21 e 30 anos de trabalho.

\section{Materiais}

Os materiais utilizados para a realização da pesquisa empírica foram os seguintes: documento de anuência da escola, termo de consentimento livre, ficha de identificação dos participantes e um roteiro de entrevista. Este último foi estruturado e elaborado pelas pesquisadoras de forma a abranger os objetivos da pesquisa. As entrevistas foram gravadas em formato mp4 e posteriormente transcritas no computador.

\section{Procedimento}

Primeiramente fizemos contato com três escolas de um município do Interior do Estado do Paraná em que pretendíamos realizar a pesquisa, a fim de solicitar a autorização para a coleta de dados prevista para este estudo. Neste contato foi esclarecido que os nomes do município, das escolas e dos participantes seriam mantidos em sigilo. Também foi explicado como seria realizado o trabalho (os objetivos, métodos, procedimentos). Informamos que o documento de autorização assinado seria encaminhado ao Comitê Permanente de Ética em Pesquisa Envolvendo Seres Humanos da Universidade Estadual de Maringá.

Após o parecer favorável do Comitê de Ética, começamos a manter contato com os professores das escolas quando eles se encontravam em período de hora-atividade nas salas dos professores. O objetivo dessas idas era selecionar professores que ministravam aulas para alunos que tomavam algum tipo de medicamento para problemas de comportamento, como o TDAH, e que estivessem disponíveis e interessados em contribuir para a pesquisa.

Alguns desses entrevistados se sentiram inseguros nesse momento, alegando a possibilidade de não conseguirem responder a algumas das perguntas. Dessa maneira, apresentávamos o roteiro de entrevista para que pudessem ler as questões antes da atividade e, assim, decidir se participariam ou não da pesquisa.

\section{Resultados e discussão}

Para a organização das informações obtidas por meio das entrevistas foi utilizada a análise de conteúdo. Chizzotti (1991) explica que este é um método de 
tratamento e análise das informações, das formas como nossos participantes configuram o social. Rocha e Deusdará (2005) complementam afirmando que a análise de conteúdo consiste em captar uma mensagem que está por trás da superfície textual, sendo utilizada para o tratamento de dados com vista a identificar o que está sendo dito a respeito de determinado tema.

Assim, nesta parte do texto iremos apresentar a análise das entrevistas de acordo com algumas das principais questões tratadas com os participantes, pois desta forma poderemos compreender de forma mais fiel as ideias, concepções e informações dos professores.

\section{O que leva o aluno a ser encaminhado ao médico}

As respostas à primeira pergunta feita aos professores - o que levaria a encaminhar o aluno ao médico - tiveram um aspecto em comum: o que há primeiramente é um problema de comportamento. Nesse sentido, um participante ${ }^{2}$ revela: "Geralmente, é o comportamento que a gente vê, que não é adequado para a sala de aula" (P4). Nessa mesma direção, outro afirma: "é a questão do comportamento dele em sala de aula" (P10).

Com relação a esses comportamentos, as respostas das entrevistas tiveram vários aspectos em comum. Entre esses aspectos, destacaremos alguns que mais apareceram e aqueles que nos chamaram a atenção:

Esses alunos muitas vezes não conseguem ficar em sala de aula, ficam andando pelo colégio e apresentam comportamento agressivo. Outras vezes, os alunos são dóceis, mas apresentam uma grande falta de atenção, como, por exemplo, quando cai um lápis em sala, já se desconcentra completamente na atividade (P1).

Sobre essa fala, pudemos observar que alguns professores relataram existirem dois tipos de aluno que chamam a atenção. Um deles é aquele aluno que é muito agitado, não fica parado na carteira, anda pela escola, é indisciplinado e agressivo. $\mathrm{O}$ aspecto da agressividade também é chamado pelos professores de "indisciplina". "Ele (o aluno) está bem, e quando você pede para ele realizar uma atividade, ele não faz, parece que ele quer fazer tudo ao contrário do que você pede" (P4). Há uma preocupação por parte do professor, já que nesses momentos o aluno está sempre se confrontando com ele. E então, "[...] a gente chega num momento em que não tem como mais conversar com o aluno e tem que mandar o aluno para uma coordenação. E a repetição desses fatos faz com que haja o encaminhamento para o médico" (P4).

Concomitantemente, existe aquele aluno que não é indisciplinado, agressivo, ou agitado. Este aluno é carinhoso, amoroso, no entanto, apresenta falta de concentração/desatenção, o que o faz dispersar em sala de aula e não conseguir realizar as atividades escolares. Assim, apesar de não haver agressividade ou indisciplina, a desatenção existe, além da falta de iniciativa: "Ela [a aluna] é muito carente, é muito amorosa, mas realmente ela não

\footnotetext{
${ }^{2}$ Para diferenciar os participantes das entrevistas, resguardando o sigilo dos indivíduos, utilizaremos neste trabalho P1 (participante número 1), P2 (participante número 2), $\mathrm{P} 3$ (participante número 3) e assim por diante.
}

quer estudar" (P10); "Tem uma criança cuja professora vinha falar pra mim: 'Ah, ele está muito distraído'. Foi o primeiro caso ao contrário do aluno agitado" (P6).

É importante que frisemos que um dos fatores que implica nesse encaminhamento não é somente o déficit de aprendizagem, até porque "[...] ele (o aluno) entendia. Só que ele ficava brincando com as mãos, ele ficava furando a borracha, ele ficava no mundo dele" (P6). Esse tipo de atividade é, para o professor, um ato de desatenção/desconcentração. "Tem aluno que não consegue se concentrar na atividade. Esses alunos geralmente começam uma atividade, mas não têm um meio e não finalizam" (P7).

A falta de concentração também se revela naquilo que os professores chamam de "dispersão em sala de aula". Como exemplo eles citam: não parar quieto na carteira, não conseguir ficar em sala de aula, falta de interesse pelas disciplinas e ficar andando pelo colégio; porém muitas vezes o que os educadores chamam de "falta de atenção" pode entrar em contradição com o que entendem por "querer chamar a atenção", como se pode observar na fala de um dos participantes: "[...] exatamente por querer chamar a atenção demais, o aluno começa a andar pela sala de aula, pedindo a atenção de seus colegas" (P6).

Sobre essa falta de concentração, uma professora chamou a atenção quando relatou que é essa desconcentração/desatenção que provoca o déficit de aprendizagem. Além disso, a consequência da falta de concentração que o aluno apresenta, em muitos momentos, é a indisciplina.

Sobre todos esses aspectos abordados e relatados na primeira questão, podemos avaliar que prevalece uma compreensão naturalizante sobre as funções "concentração", "atenção" e "comportamento inadequado". Na maioria das falas apresentadas nessa questão verificamos a ideia de que a falta de concentração é algo intrínseco ao indivíduo. Essa inadequação do comportamento revela-se até mesmo naquilo que os professores denominam "falta de vontade": "Não é questão de não estar prestando atenção na aula porque é normal, mas porque não quer prestar atenção, não quer fazer alguma coisa, ou dorme" (P10).

Segundo Leite (2010), a concepção biológica da desatenção escolar é hegemônica na sociedade capitalista, e parte da ideia de que há uma disfunção cerebral orgânica que leva esse aluno a sofrer de algum distúrbio de déficit de atenção. A literatura hegemônica, segundo essa mesma autora, aproxima-se do discurso dos professores que foram entrevistados.

Esse tipo de entendimento foi frequentemente observado na fala dos professores, como exemplificado anteriormente, o que demonstra um discurso hegemônico do problema da desatenção do comportamento escolar. Voltando à história do processo de medicalização, percebemos, através das falas de alguns participantes, que a naturalização dos problemas de comportamento 
na escola existe e que o aluno é responsabilizado pelo problema escolar, pois, por exemplo, relatam que a falta de atenção ocorre por vontade própria do aluno.

Concomitantemente ao que se observou nas primeiras falas das entrevistas, pudemos identificar, já nesse momento, os sentimentos quanto à preocupação dos professores com os problemas de comportamento em sala de aula. O que pudemos analisar foi um sentimento de impotência dos educadores, que, por não conseguirem se inserir como parte ativa no processo de ensino e aprendizagem de seus alunos, também não se sentem capazes de influir nesse processo.

Dessa forma, o que resta a esses professores é buscar alternativas que são apresentadas no ambiente escolar como solução para os problemas de comportamento, de forma a-histórica. $\mathrm{O}$ encaminhamento ao médico é uma dessas alternativas, que identificamos como privatização/ terceirização do ensino nos moldes capitalistas:

A entrada da medicina no ambiente escolar torna-se, assim, "a pedra filosofal" para responder aos problemas de comportamentos dos alunos indisciplinados, mal-educados, agressivos e desatentos. Como uma das formas de procurar solucionar esses problemas sociais, os medicamentos psicotrópicos se transformam em mercadorias para o consumo na educação, ${ }^{3}$ eliminando os problemas de comportamento nas escolas. Para identificarmos essa inserção, vamos ao segundo questionamento.

\section{Qual a medicação que o aluno toma}

A Ritalina (nome científico: metilfenidato) é o medicamento mais utilizado para eliminar problemas de comportamento na escola. Todos os dez professores entrevistados revelaram que a Ritalina é o medicamento mais conhecido e mais utilizado pela comunidade escolar estadual.

Cumpre lembrar que a Ritalina pode estar associada a outros medicamentos. Alguns professores relataram que, além do déficit de atenção e hiperatividade, esses mesmos alunos apresentavam o problema da depressão. Dessa forma, foi frequente encontrar relatos afirmando que alguns alunos tomam Ritalina associada a algum medicamento antidepressivo, como o Tofranil. Segundo um dos participantes, a depressão desse aluno era percebida quando "[...] o aluno ficava sempre distraído, no mundo dele" (P6).

É importante considerar que a Ritalina é um psicotrópico de curta duração e apresenta efeitos colaterais visíveis, além de ser muito criticado pela ciência médica que atua na contramão do processo de medicalização. Segundo Moysés e Collares (2010), a Ritalina possui um efeito de toxicidade no organismo do indivíduo, o que significa que o uso prolongado desse medicamento provoca no organismo e na vida social muito mais efeitos prejudiciais do que os efeitos benéficos.

\footnotetext{
${ }^{3}$ Existem outros mecanismos que buscam solucionar os problemas sociais na educação, como os conselhos tutelares e as patrulhas escolares, mas que não serão analisados neste trabalho.
}

O outro tipo de medicamento relatado entre os participantes ( 2 entre 10 professores disseram conhecer esse medicamento) para tratar do "aluno-problema" foi o Concerta. A venda desse medicamento é controlado no Brasil por ser um psicotrópico importado, portanto, seu preço é maior que o da Ritalina. De acordo com Moysés e Collares (2010), recentemente o medicamento Concerta foi liberado para a venda no Brasil. Os demais, como a dextro-anfetamina (D-anfetamina - com o nome comercial Adderall) ainda não foram liberadas no país.

O princípio ativo do Concerta é o cloridrato de metilfenidato, que também faz parte da classe terapêutica dos psicoestimulantes, assim como a Ritalina, mas é um medicamento mais recente, que apresenta liberação prolongada no organismo. Esse psicotrópico vem sendo muito utilizado por adultos que buscam melhorar a produtividade nos estudos e no trabalho. ${ }^{4}$ Barkley (2008) apontou-o como algo que evitaria a exposição da criança à tomada do medicamento na escola, poupando-a de expor seu problema a outros colegas e pessoas de suas relações.

Essas informações a respeito do uso de psicotrópicos de efeito prolongado em crianças com problemas de comportamento nos leva a refletir sobre o verdadeiro papel desses medicamentos na vida desses indivíduos. Muito mais que prometerem a melhora da concentração e aprendizagem dessas crianças, medicamentos como o Concerta prometem um tipo de comportamento esperado na sociedade capitalista, aquele que tende à disciplina e à produção em larga escala. Além disso, esses medicamentos são mais uma forma terceirizada de educar os filhos. Ao eliminar comportamentos inadequados, o Concerta libera a sociedade e os pais do ônus de educar seus filhos.

Dessa maneira, seja qual for o medicamento utilizado para os problemas de comportamento, o paradigma que está se construindo é que o uso cada vez mais frequente de psicotrópicos é uma arma contra os problemas advindos da sociedade moderna. Isso pode ser percebido nos relatos dos professores. O uso de medicamentos vem se tornando algo naturalizado pela escola, de modo que o aluno pode tomar mais de um medicamento num período de quatro horas e, além disso, até mesmo o professor acaba lhe ministrando esse medicamento. " $\dot{A} s$ vezes o aluno, dependendo da gravidade do problema, toma mais de uma medicação. Tem casos em que o aluno toma o medicamento na própria escola, e tem vezes que o próprio professor ministra o medicamento" (P1).

Essa fala nos leva a analisar a inserção do professor no processo de medicalização. Observamos que há nisso uma contradição, pois o professor, ao mesmo tempo em que não se encontra inserido no processo de ensino, reafirma essa exclusão quando entende que é a medicação que irá resolver o problema do aluno. Sobre isso, Costa, Fernandes Neto e Souza (2009) revelam que a alienação na sociedade capitalista acontece também na escola, e que em seu o trabalho o professor não se percebe mais inserido no processo de ensino

\footnotetext{
${ }^{4}$ Informação disponível no website da Federação Brasileira de Redes Associativas de Farmácia (FEBRAFAR): <http://www.febrafar.com.br/index.php?cat $\mathrm{id}=5 \&$ pag_id=3062>. Acesso em: 24 ago. 2011.
}

Fractal, Rev. Psicol., v. 28 - n. 1, p. 46-54, 2016 
exatamente porque a mercantilização da educação leva a escola a atuar como uma empresa, reproduzindo os modelos privatizantes da sociedade capitalista

O não reconhecimento do trabalho do professor como mediador da construção da aprendizagem e desenvolvimento, assim como o não reconhecimento do aluno como matéria-prima do seu trabalho, apresenta-se de forma objetivada no processo de medicalização na sociedade atual. O professor passa a dar importância ao medicamento, pois já não consegue administrar a relação escolar. Ao mesmo tempo, tornando-se "redentor"s da sociedade no Estado burguês, esse professor se encontra respaldado pela medicação, quando precisa dela para que a aprendizagem ocorra nos limites da escola.

A seguir analisaremos algumas falas desses professores sobre a importância da medicação na eliminação dos comportamentos escolares inadequados.

\section{O uso da medicação e sua importância}

Nas falas dos professores identificamos a influência do medicamento no comportamento dos alunos em sala de aula. Essa influência se dá em dois aspectos. O primeiro é que se acredita que o aluno medicado consegue se concentrar mais e fazer as atividades em sala de aula, passando a produzir satisfatoriamente. Além disso, os professores afirmam que o medicamento ajuda o aluno a ficar mais calmo.

Pudemos notar a compreensão de que a importância do metilfenidato está em que ele acalma o aluno e promove sua concentração. Além disso, o medicamento o ajudaria a centrar-se em alguma atividade e evitaria a dispersão. Quando ocorre essa falta de concentração e essa dispersão o aluno não desenvolveria atividades nem se apropriaria do conhecimento, daí advindo o fracasso escolar. Pelos relatos dos professores, o fracasso escolar poderia ser reduzido com o uso de medicamentos. Dessa maneira, observa-se que, ao invés de compreender o problema do insucesso escolar por raízes históricas, como aponta Patto (2010), busca-se explicar esse problema numa perspectiva individualizante e biologizante.

Superando as concepções de que a não produção do aluno vem da falta de cultura (teoria da carência cultural) ou de alguma disfunção cerebral deste. Patto (2010) afirma que o insucesso escolar vem de uma construção baseada na estrutura de classes da sociedade, a qual reproduz a ideologia burguesa, e para isso, necessita rotular o aluno proveniente das classes trabalhadoras como não apto para o trabalho intelectual e promover aquele aluno advindo da burguesia como apto para tal tipo de trabalho.

Esse tipo de compreensão histórica e social não se verifica em uma forma de compreensão organicista e unilateral dos escolares. Se observarmos a questão somente pelo aspecto físico, o uso de psicotrópicos como a Ritalina produz como efeito o aumento da concentração e da produção, além de ser responsável

\footnotetext{
Este termo foi utilizado pela professora Amanda Gurgel em 2011, quando apresentou uma fala de manifesto dos professores pela qualidade da educação em uma discussão de vereadores sobre a Educação e a greve dos professores no Estado do Rio Grande do Norte, cidade de Natal. Disponível em: <http://www. youtube.com/watch?v=yFkt0O7lceA>. Acesso em: 20 jul. 2011.
}

pela sensação de prazer no uso dessa droga lícita. Moysés e Collares (2010) afirmam que o efeito do metilfenidato é o mesmo da cocaína: ambos possuem um mecanismo de ação estimulante que intensifica a atenção e a produtividade do indivíduo.

Tendo analisado as pesquisas realizadas com o uso de metilfenidato em indivíduos que praticam esportes, essas mesmas autoras afirmam que os resultados são parecidos com os resultados em estudantes diagnosticados com TDAH: a melhora do desempenho; no entanto, o efeito colateral quase não é percebido por esses atletas que ingerem o metilfenidato, já que provocam uma sensação de bem-estar em curto prazo, Afirmam elas que

[...] a combinação da inibição da recaptação de dopamina e exercício em temperatura alta melhora o desempenho e eleva a temperatura corpórea, sem que o indivíduo perceba o esforço ou o stress térmico, o que aumenta o risco de hipertermia durante exercício em pessoas que tomem drogas desse tipo (MOYSÉS; COLLARES, 2010, p. 99).

As mesmas autoras afirmam que também há um efeito colateral do metilfenidato quando ingerido por alunos, que é o aumento da sensação de prazer através do aumento dos níveis de dopamina. Explicam que

[...] o cérebro torna-se dessensibilizado a situações comuns da vida que provocam prazer, como alimentos, emoções, interações sociais, afetos, o que leva à busca contínua do prazer provocado pela droga, culminando na drogadição. Além disso, especula-se se aumentos desnecessários da dopamina durante a infância poderiam alterar o desenvolvimento do cérebro. Como a medicação costuma ser retirada em torno dos 18 anos, esses jovens podem se tornar adeptos da cocaína na vida adulta, como modo de substituir a droga legal que tomaram por anos (MOYSÉS; COLLARES, 2010, p. 97).

Esses aspectos importantes dos efeitos do metilfenidato são apresentados nas falas de alguns professores:

Eu não sei, uns (alunos) reclamam do uso: 'professora, eu não gosto de tomar, eu perco o apetite, eu tenho sono'. As reações são diversas. Mas... não sei o que é positivo, a gente não sabe até onde (P3);

Alguns outros alunos ficam apáticos até demais. Não sei se uns reagem bem, outros não (P6);

Tem aluno que fica extremamente prostrado, não faz nada (P7).

No entendimento de um professor entrevistado, a criança que faz uso de medicação perde sua infância: "[...] ele (o aluno) fica mecânico, passa essa fase da vida e de repente lá na frente vai fazer falta, então, ele vai dar trabalho lá na adolescência, porque ele não curtiu a infância. Eu, particularmente, não sei se eu usaria em meu filho" (P9). Na compreensão de outro professor, o uso da Ritalina é muito prejudicial, pois pode provocar uma dependência futuramente: "[...] a questão é que o remédio vai complicar muito a vida dela futuramente. [...] é uma coisa que cria uma dependência, é muito forte. Acho que para a criança, jamais" (P10). 
A partir dessas considerações sobre as implicações do uso de medicamentos para resolver problemas educacionais e sociais, é importante retomarmos o aspecto das consequências físicas futuras para alunos que fazem uso de alguma droga em um período de desenvolvimento importante para a formação do psiquismo humano.

\section{Afirmam Moysés e Collares (2010, p. 102):}

O metilfenidato é responsável por um outro problema, extremamente sério: 30 a $50 \%$ dos jovens em tratamento em clínicas para drogaditos relatam o uso abusivo de Ritalina, que tem se tornado a droga de escolha para adolescentes, por ser relativamente barata, acessível e, principalmente, por ser percebida como segura, uma vez que é prescrita por médicos. Confrontando com esses dados, autores que defendem a existência dessa entidade e necessidade de tratamento, pretendem que a tendência a drogadição e comportamento delinquente seriam sinais de TDAH. A Ritalina, em altas doses, ou se injetada ou inalada, é tão aditiva quanto a cocaína. Conforme o cérebro se adapta à presença contínua da droga, afeta áreas cerebrais responsáveis por memória, aprendizagem e julgamentos; essas regiões começam a se alterar fisicamente. A procura por droga torna-se quase reflexa, mecanismo pelo qual um usuário de droga torna-se drogadito.

Perguntamos entãoserealmenteouso demedicamentos que melhoram momentaneamente a aprendizagem e a atenção da criança compensa os preços futuros que essa criança poderá ter que pagar. Questionamos também qual a verdadeira função desses psicotrópicos, uma vez que perpassam o discurso da melhora da concentração e da aprendizagem de indivíduos medicalizados. É possível refletir sobre o controle social que esses medicamentos podem proporcionar, no sentido de rotular, estigmatizar e excluir os seres humanos do processo de humanização através do trabalho (MOYSÉS; COLLARES, 2010). De acordo com Rose (2008, p. 521), “[...] crianças recebendo Ritalina por prescrição médica estão sendo drogadas como método de controle social. Isto é, me parece, uma questão ética real. Se nós não reconhecemos a situação do mundo real em que drogas são compradas, prescritas e usadas, então o debate ético é vazio".

A questão do debate ético também recai sobre a maneira como o indivíduo vem sendo responsabilizado por problemas muito mais amplos do que simplesmente explicar o fracasso escolar de forma orgânica ou psíquica. O controle social também se dá quando o discurso ideológico responsabiliza a família por um problema que ultrapassa essas fronteiras. Desta forma, também se está individualizando a questão dos problemas escolares. Este foi um aspecto observado nas entrevistas de maneira muito frequente.

Assim, a causa dos problemas de comportamento estaria muito mais relacionada aos problemas familiares, como o que aponta o relato destas participantes:

[...] todos os casos de ritalina, a maioria deles é caso de instabilidade familiar. Não tem um caso de ritalina que eu posso te citar que eu falo: mas aqui a familia cuida aqui. A maioria dos casos é tudo desestruturado. E é o que a gente estava falando, é social, e está desembocando aí. Eu não sei o que é melhor ou pior? (P3);

[...] tudo o que você vai analisar de uma criança dessa, a maioria dos problemas está na familia, há uma desestruturação familiar, e isso reflete em sala de aula, reflete no comportamento dele, reflete na aprendizagem [...] (P7);

Consideramos relevante destacar que os problemas de escolarização, sobretudo os comportamentos dos alunos considerados inadequados, não devem ser compreendidos de forma isolada, isto é, apenas do ponto de vista do aluno ou de sua família, e sim, no contexto escolar, social e histórico. $\mathrm{O}$ aluno não é um ser a-histórico a-social, ele pertence a uma sociedade e a uma cultura. Conforme Vigotski (1991), os fatores biológicos são preponderantes apenas no início da vida da criança e são responsáveis pelas funções psicológicas elementares (reações automáticas e ações reflexas). De acordo com Leontiev (1978), as funções psicológicas superiores (memória, atenção, pensamento abstrato e outras) são especificamente humanas e se formam nas relações sociais entre os homens, no processo de produção da vida e por meio da apropriação da cultura humana transmitida de geração a geração.

\section{Considerações finais}

Analisando a sociedade capitalista, e articulando sua história com a maneira como as relações sociais e os processos educativos vêm sendo produzidos, chegamos à conclusão de que a apropriação da cultura não está sendo feita de maneira efetiva na escola, uma vez que os índices de repetência escolar aumentam a cada ano. Somando-se a isto, a alienação do trabalho do professor nos moldes capitalistas vem contribuindo para a precarização do ensino, uma vez que não se proporcionam a esse profissional as condições mínimas necessárias para exercer seu trabalho de forma plena.

Uma das maneiras de essa configuração se refletir na escola de hoje é o processo de medicalização dos problemas escolares. Pudemos perceber, por meio das entrevistas com os professores, que a aplicação de medicamentos em alunos que apresentam problema de comportamento atesta o esvaziamento das relações sociais estabelecidas na escola, com o embotamento do trabalho do professor, que não se percebe como parte ativa no processo de aprendizagem dos alunos, e o próprio embotamento do aluno, que acaba absorvendo o discurso hegemônico da naturalização dos fenômenos sociais.

Outra forma de expressão da medicalização dos problemas escolares é a entrada dos "especialistas da educação" que, ao apontarem que o problema de ensino está no próprio aluno, reafirmam o embotamento do professor e do alunado nas relações educativas. Pudemos compreender que essa é uma característica da sociedade capitalista que tende para a privatização/terceirização do ensino, que segue a lógica de intervenção mínima do governo na vida das pessoas e de inserção dos serviços privados. Esse processo isenta o Estado de responsabilidade pela condição de vida da sociedade e responsabiliza o indivíduo pelos problemas que ocorrerem com ele. 
Todos esses fatores que contribuem para a precarização do ensino e naturalização dos fatos sociais possuem contradições que puderam ser mais bem compreendidas pela entrevista com os professores. $O$ fato de que a medicina não tem posições claras e definidas a respeito dos diagnósticos que vem realizando para o problema de comportamento e atenção dos alunos mostra que o discurso da naturalização do social fracassa em alguns momentos. Isto pôde ser percebido por meio dos relatos dos professores, quando apontaram que nem todos os alunos que tomam medicamento para o problema de comportamento sentem uma melhora significativa. Ora, se as dificuldades de se comportar e de se concentrar em sala de aula estão relacionadas a um problema orgânico e/ou neurológico, a tomada dos medicamentos deveria responder às necessidades orgânicas apontadas pelos especialistas.

Neste sentido, foi possível captarmos a reflexão dos próprios professores a respeito das consequências do uso de medicamentos para a resolução de problemas escolares: apesar de, por um curto prazo, haver uma melhora da capacidade de concentração e da disciplina em sala de aula, esse tipo de melhora ocorre ao custo de o aluno se tornar apático e isolado do ambiente escolar e da relação com os colegas de sala. Essa reflexão pôde ser respaldada pelas pesquisas teóricas que realizamos, as quais mostram que os efeitos a longo prazo do uso dessas drogas são de dimensões desconhecidas e incertas, levando-nos a questionar a ética nesse tipo de prática social.

Uma observação importante a fazer é que a comunidade científica admite que esses medicamentos possuem o mesmo mecanismo de ação que drogas como, por exemplo, a cocaína, promovendo a curto prazo uma sensação de bem-estar e melhora no rendimento. Além disso, a dependência causada pelo uso desses medicamentos faz com que essa mesma comunidade (não) conheça a dimensão das consequências futuras desse processo na vida posterior de alunos assim "medicados". Neste momento, é difícil admitir que a consequência do uso desses medicamentos não seja apenas a melhora da aprendizagem e do comportamento do aluno: na realidade esse uso visa a um controle social que pode vir a responder a necessidades ideológicas ou de outra ordem.

As implicações do processo de medicalização para a infância também são de dimensões ainda não explicadas. Aqui tratamos de referendar o relato dos professores ao afirmarem que os alunos se tornam apáticos e não se relacionam mais com os colegas da maneira como se relacionavam antes. É possível que os medicamentos estejam prejudicando aspectos importantes da infância, como o de se apropriar da qualidade nas suas relações pessoais ou sociais. Partindo de considerações como essas, é possível questionar se na sociedade em que vivemos atualmente a qualidade das relações é importante. O que nos parece mais plausível é o fato de que na sociedade capitalista em questão o que importa é a liberdade de trocas comerciais, e não a liberdade nas relações sociais. Para o capitalismo, o controle social é um aspecto primordial para atender às demandas do mercado. Assim, controlar o comportamento dos indivíduos ultrapassa a necessidade mais superficial de atender aos problemas de comportamento e aprendizagem dos alunos.

A prática social da medicalização dos problemas de comportamento de alunos nas instituições escolares se torna uma prática social de controle, uma vez que com essa ação se buscam objetivos materiais ideológicos. Em nossa perspectiva, esse tipo de prática não consegue responder às demandas da instituição escolar para os problemas de comportamento dos alunos. É preciso repensar as dimensões éticas e políticas que estão sendo utilizadas na vida desses estudantes para atender ao mercado capitalista. Dessa maneira, pensamos que há possibilidades, por mais remotas que pareçam, de construir novos tipos de relações nos diferentes espaços sociais, entre eles o escolar.

\section{Referências}

AMERICAN PSYCHIATRIC ASSOCIATION. Diagnostic and Statistical Manual Of Mentaldisorders (DSM-IV). $4^{\text {th }}$ ed. Washington: American Psychiatric Association, 1994.

BARROS, J. A. C. Estratégias mercadológicas da indústria farmacêutica e o consumo de medicamentos. Revista Saúde Pública, São Paulo, v. 17, n. 5 p. 377-386, 1983.

BARKLEY, R. A. Transtorno de déficit de atenção/ hiperatividade: manual para diagnóstico e tratamento. 3. ed. Tradução de Ronaldo Cataldo Costa. Porto Alegre: Artmed, 2008.

BOARINI, M. L.; BORGES, R. F. Hiperatividade, higiene mental, psicotrópicos: enigmas da Caixa de Pandora. Maringá: Eduem, 2009.

BRZOZOWSKI, F. S.; CAPONI, S. N. C. Medicalização dos desvios de comportamento na infância: aspectos positivos e negativos. Psicologia Ciência Profissão, Brasília, v. 33, n. 1 p. 208-219, 2013.

CALIMAN L. V. O TDAH: entre as funções, disfunções e otimização da atenção. Psicologia em Estudo, Maringá, v. 13, n. 3, p. 559-566, 2008.

CHIZZOTTI, A. Pesquisa em ciências humanas e sociais. São Paulo: Cortez, 1991.

COSTA, A.; FERNANDES NETO, E.; SOUZA, G. A proletarização do professor: neoliberalismo na educação. 2. ed. São Paulo: Instituto José Luiz e Rosa Sundermann, 2009.

COLlARES, C. A. L.; MOYSÉS, M. A. A. Preconceitos no cotidiano escolar: a medicalização do processo ensino-aprendizagem. In: CONSELHO REGIONAL DE PSICOLOGIA DE SÃO PAULO (Org.). Medicalização de crianças e adolescentes: conflitos silenciados pela redução de questões sociais a doença de indivíduos. São Paulo: Casa do Psicólogo, 2010. p. 193-213.

CONRAD, P. The medicalization of society: on the transformation of human condition into treatable disorders. Baltimore: The Johns Hopkins University Press, 2007.

EIDT, N. M.; TULESKI, S. C. Transtorno de Déficit de Atenção/ Hiperatividade e Psicologia Histórico-Cultural. Cadernos de Pesquisa, [S.1.], v. 40 n. 139, p. 121-146, jan/abr, 2010. 
GARRIDO, J.; MOYSÉS, M. A. A. Um panorama nacional dos estudos sobre a medicalização da aprendizagem de crianças em idade escolar. In: CONSELHO REGIONAL DE PSICOLOGIA DE SÃO PAULO (Org.). Medicalização de Crianças $e$ Adolescentes: conflitos silenciados pela redução de questões sociais a doenças de indivíduos. São Paulo: Casa do Psicólogo, 2010. p. 149-162.

GUARIDO, R.; VOLTOLINI, R. O que não tem remédio, remediado está? Educação em Revista, Belo Horizonte, v. 25, n. 1, p. 239-263, abr. 2009.

GUSMÃO, M. M. G. Comportamento infantil conhecido como hiperatividade: consequência do mundo contemporâneo ou TDAH?. 2009. 127 f. Dissertação (Mestrado em Educação)Universidade Federal de Minas Gerais, Belo Horizonte, 2009.

KANTOVISKI, A. L. L.; VARGENS, O. M. C. O cuidado à mulher que vivencia a menopausa sob a perspectiva da desmedicalização. Revista Eletrônica de Enfermagem, [S.1.], v. 12 n. 3, p. 567-570, 2010.

LEITE, H. A. O desenvolvimento da atenção voluntária na compreensão da Psicologia Histórico-Cultural: uma contribuição para o estudo da desatenção e dos comportamentos hiperativo. 2010. 197 f. Dissertação (Mestrado em Psicologia) Universidade Estadual de Maringá, Maringá-PR, 2010.

LEONTIEV, A. N. O desenvolvimento do psiquismo na criança. In: _. O desenvolvimento do psiquismo. Lisboa: Livros Horizonte. 1978. p. 287-313.

LUENGO, F. C.; CONSTANTINO, E. P. A Vigilância Punitiva: a postura dos educadores no processo de patologização e medicalização da infância. Revista de Psicologia da UNESP, Assis, v. 8, n. 2, p. 22-126, 2009.

MOYSÉS, M. A. A.; COLLARES, C. A. L. Dislexia e TDAH: uma análise a partir da ciência médica. In: CONSELHO REGIONAL DE PSICOLOGIA DE SÃO PAULO (Org.). Medicalização de Crianças e Adolescentes: conflitos silenciados pela redução de questões sociais a doenças de indivíduos. São Paulo: Casa do Psicólogo, 2010. p. 71-110.

PATTO, M. H. S. A produção do fracasso escolar: histórias de submissão e rebeldia. São Paulo: Casa do Psicólogo. 2010.

ROCHA, D.; DEUSDARÁ, B. Análise de conteúdo e análise do discurso: aproximações e afastamentos na (re) construção de uma trajetória. Alea-Estudos Neolatinos, v. 7, n. 2, 2005. Disponível em: $\quad<$ http://www.scielo.br/scielo.php?script=sci arttext\&pid $=\mathrm{S} 1517-106 \mathrm{X} 2005000200010>$. Acesso em: 27 jun. 2008.

ROSE, S. Drugging unruly children is a method of social control. Nature, London, v. 451, n. 7178, p. 521, Jan. 2008.

SOUZA, M. P. R.; CUNHA, B. B. B. Projetos de Lei e políticas públicas: o que a psicologia tem a propor para a Educação? In: CONSELHO REGIONAL DE PSICOLOGIA DE SÃO PAULO (Org.). Medicalização de crianças e adolescentes: conflitos silenciados pela redução de questões sociais a doença de indivíduos. São Paulo: Casa do Psicólogo, 2010. p. 215-227.

VALENTINE, K. A consideration of medicalisation: choice, engagement and other responsibilities of parents of children with autism spectrum disorder. Social Science and Medicine, Austrália, v. 71, n. 5, p. 950-957, 2010.

VIGOTSKI, L. S. Pensamento e Linguagem. 3. ed. São Paulo: Martins Fontes, 1991.
Recebido em: 18 de jul. 2013

Aceito em: 25 set. 2015 